Portland State University

PDXScholar

\title{
A Review of Methodologies Applied for Determining Particulate Matter Characterization in Urban Regions
}

Garrett F. Diehl

Portland State University

Follow this and additional works at: https://pdxscholar.library.pdx.edu/honorstheses

Part of the Chemistry Commons

Let us know how access to this document benefits you.

\section{Recommended Citation}

Diehl, Garrett F., "A Review of Methodologies Applied for Determining Particulate Matter Characterization in Urban Regions" (2020). University Honors Theses. Paper 869.

https://doi.org/10.15760/honors.890

This Thesis is brought to you for free and open access. It has been accepted for inclusion in University Honors Theses by an authorized administrator of PDXScholar. Please contact us if we can make this document more accessible: pdxscholar@pdx.edu. 


\title{
A Review of Methodologies Applied for Determining Particulate Matter
} Characterization in Urban Regions

\author{
by \\ Garrett F. Diehl \\ An undergraduate honors thesis submitted in partial fulfillment of the \\ requirements for the degree of \\ Bachelor of Science \\ in \\ University Honors \\ and
}

Chemistry

Thesis Adviser

Ph.D. Olyssa Starry

Portland State University

2020

P a g e 1 | 15 


\begin{abstract}
:
This is a literature review on previous research conducted on particulate matter deposited on urban vegetation. This was accomplished by searching six databases, that uncovered 37 peerreviewed journal articles. The main objective of this review is to present the methodology and findings of the articles analyzed to demonstrate how research in this area of study is being conducted. The findings show that there are variations in the literature and that many variables are not being incorporated into the methods and analyses of particulate matter found on urban vegetation. Understanding how different studies have analyzed particulate matter found on urban vegetation will be essential in determining if a standard method should be implemented to produce more consistent data and results. This will be vital in determining which plants and trees can reduce the most harmful pollutants in urban areas and as a result improve air quality.
\end{abstract}

\title{
1. Overview
}

According to the World Health Organization (WHO), approximately 4.6 million people die each year from causes directly related to air pollution (WHO et al., 2005). Children seem to be particularly susceptible to air pollution because of their developing heart and lungs (Salvi et al., 2007). Short-term exposure to air pollution can cause an increase in cardiopulmonary diseases, while long-term exposure can lead to chronic diseases, such as lung cancer, resulting in reduction of life expectancy (WHO et al., 2005).

Air pollution is mainly of anthropogenic origin. That is, vehicular traffic and component wear (Yang et al., 2018). The main components of air pollution are particulates, ozone $\left(\mathrm{O}_{3}\right)$, nitrogen dioxide $\left(\mathrm{NO}_{2}\right)$, and sulfur dioxide $\left(\mathrm{SO}_{2}\right)$. Particulate matter $(\mathrm{PM})$ is a complex mixture of small particles $(\sim \mu \mathrm{m})$ and liquid droplets that consist of organic chemicals (e.g. VOCs and PAHs), inorganic metals (e.g. $\mathrm{Cd}, \mathrm{Zn}, \mathrm{Cr}, \mathrm{Cu}, \mathrm{As}$, and $\mathrm{Pb}$ ), acids (e.g. nitrates and sulfates), and other substances (Lindley et al., 2012). The size or aerodynamic diameter of PM is an important characteristic because it determines its behavior and toxicity in the human body and other biological species. Smaller particles, less than $2.5 \mu \mathrm{m}$ in diameter can easily penetrate deep into our respiratory and circulatory system, damaging our lungs, heart, and brain (WHO et al., 2005; Burkhardt et al., 2018).

Particulates are often defined as coarse ( $\left.\mathrm{PM}_{2.5}-10 \mu \mathrm{m}\right)$, fine $\left(\mathrm{PM}_{0.1-2.5} \mu \mathrm{m}\right)$, and ultra-fine ( $\leq$ PM $0.1 \mu \mathrm{m})$. Some heavy metals are essential to maintain normal human body functions at trace amounts. However, they may be dangerous or even toxic if present at higher concentrations. Heavy metals such as lead, cadmium, zinc, and arsenic are substantially toxic elements known for their ability to bioaccumulate in the human body, resulting in multi-organ disruption (Sæbø et al., 2012). For example, once cadmium is absorbed into the human body, it can accumulate in the kidneys and remain in the body for decades (EPA et al., 2012).

Plants and trees have been shown to play an important role in filtering ambient air. This removal of pollution from the environment is called phytoremediation. Phytoremediation has been shown to be a solution for air quality improvements due to this technique being easy to introduce, 
relatively inexpensive, and an environmentally friendly biotechnology (Dzierżanowski et al., 2011). The four processes that are responsible for the deposition process of PM are sedimentation under gravity, diffusion, turbulent transfer, which contributes to impaction and interception (Petroff et al., 2008). In addition, the structure of tree crowns can cause turbulent air movements which can result in an increase in the PM deposition process onto leaves (Fowler et al., 1989). Studies have shown that trees, plants, and other vegetation are highly effective at accumulating many of these toxic PMs found in urban areas. For example, Acer pseudo platanus L. has been used as a bioindicator for assessing air contamination (André et al., 2012) in urban ecosystems in Europe, and Quercus ilex L. has been used as a bio-accumulator for heavy metals in urban areas (Ugolini et al., 2013).

Studies have demonstrated that this technique can purify air and can increase the air quality and as a result, could increase life expectancy (Sæbø et al., 2012; Dzierżanowski et al., 2011). One study measured that 772 tons of $\mathrm{PM}_{10}$ was removed by trees during one year in the city center of Beijing, China (Yang et al., 2005). Two studies conducted in Chicago, Illinois used a model, called the iTree model, to determine that urban trees that occupy approximately $11 \%$ of the metro area removed about 234 tons of $\mathrm{PM}_{10}$ from the environment (Nowak et al., 1994) and in the United States, urban trees remove about 215,000 tons of $\mathrm{PM}_{10}$ every year (Nowak et al. 2006). This was disputed by a research plant ecologist, Tom Whitlow, and his team because Nowak's model does not consider many of the variables of the deposition process. Whitlow believes that the ability of plants and trees to accumulate PM is more dependent on dispersion due to turbulent flow and location to pollutants. In addition, if landscape designers intend to use trees in designing landscapes to reduce exposure to air pollution, then a simple "more trees are better" approach is inadequate and fails to account for the deposition process of PM.

The majority of the current studies have only investigated how much PM was found on urban vegetation and not considered how different variables will affect the amount and types of PM found on urban vegetation. Such as, environment, sampling techniques, analytical methods, deposition process, and among other important variables. Therefore, the aims of this study are to compare methodologies \& findings of peer-reviewed journal articles to determine if there are disagreements in the literature and conclude if there needs to be an implemented method to ensure more accurate results. This could aid in determining which plants and trees can reduce the most harmful pollutants in urban areas and as a result improve air quality.

\section{Methodology}

\subsection{Overview}

Two main procedures were followed to ensure a high-quality review of the literature. First, a comprehensive search of peer-reviewed journal articles was conducted based on a wide range of key terms including air pollutants, phytoremediation, leaf surfaces, quantification of PM, coarse and fine particulates, urban deposition, bioindicators, and air quality. Six databases were searched including ResearchGate, Portland State University, Google Scholar, Web of Science, JSTOR, My Science Work, and ScienceDirect. Second, the reference section for each article found was 
examined in-order to find additional relevant journal articles. The search process uncovered 37 peer-reviewed journal articles published from 1989 - 2018.

\subsection{Analysis of Articles Collected}

Of the 37 peer-reviewed articles found on urban deposition, PM accumulation, and air quality, 12 articles specifically investigated PM found on leaf surfaces. An analysis of the 12 studies, revealed five particular areas of focus that will be included in this review: (1) geographical location, (2) purpose of study, (3) type of urban vegetative species analyzed, (4) method of quantification of PM, and (5) what urban vegetation species were most effective and least effective at accumulating and retaining PM. In addition, a comparison of the results of studies that used the same urban species is included in this review. These key areas of focus were then used to determine similarities and inconsistencies between each of these studies, in-order to establish if there are variations in the literature and if there needs to be an implemented method to ensure more accurate conclusions.

\section{Results}

\subsection{Geographical Location of Studies}

A World map of the studies critically analyzed in this literature review are shown in the Appendix, on page 12.

\subsection{Methods and Results of Studies Analyzed}

A table of publications, methods of quantification, sample species, geographical location, and the most \& least effective species in PM accumulation determined by the amount of PM found on the surfaces of the leaves is shown in the Appendix, on page 14.

\subsection{Purpose of Current Studies}

The leading studies performed in this field have focused on many different aspects of urban vegetation and PM accumulation. For instance, one study focused on examining the chemical characterization of different leaf surfaces and in-wax fractions to determine the concentrations of PM found on different species of urban vegetation (Deljanin et al., 2015). Another study assessed the differences between the PM concentrations found on the leaves of twelve plant species but collected samples from six different locations to determine differences due to location (Liang et al., 2017). In addition, the retention efficiency to PM of different tree species was investigated by using three elution methods to determine what tree species is more efficient at retaining PM (Liu et al., 2018). But, the majority of the studies performed have focused more on the total amount of PM deposited on the surface of the leaves by comparing different species of trees, shrubs, climbers, 
and other urban vegetation to determine the most and least effective species at accumulating PM (Dzierżanowski et al., 2011; Esposito et. al, 2018; Jouraeva et al., 2002; Sæbø et al., 2012; Shi et al., 2017).

\subsection{Methods of Quantification}

A number of techniques have been used to determine the amount of PM found on leaf surfaces. Because of this, many discrepancies have occurred which have generated inconsistent data and conclusions. For example, two studies were conducted in Beijing, China using the same three broad-leaf tree species; Salix babylonica, Ginkgo biloba, and Sophora japonica, as shown in the Appendix, on page 13. (Liu et al., 2018; Shi et al., 2017). Two different analytical techniques were used to quantify the PM composition and concentration deposited on the leaf surfaces of these tree species via ultrasonic cleaning with Gravimetric Analysis (GA) and X-Ray Fluorescence - Energy Dispersive Spectroscopy (XRF-EDS), respectively. The studies used the same sample location (Xitucheng Park, China) and concluded different results. Liu et al., concluded that Sophora japonica was the most effective at retaining fine-PM and Salix babylonica was the most efficient at retaining coarse-PM. The least effective at retaining all types of PM sizes was found to be Ginkgo biloba. Shi et al., determined that Sophora japonica was most effective at capturing ultrafine-PM, but not fine-PM, and Salix babylonica and Ginkgo biloba were most effective at fine-PM. E. japonicus was the most effective at capturing and retaining all sizes of PM. This also contradicts a similar study that determined Ginkgo biloba had the lowest concentration of PM (Liang et al., 2017). This demonstrates that using the same sample location and different analytical techniques produced variations in the findings. As a result, no conclusion can be made which urban species was the most and least effective at accumulating PM.

There have been many analytical techniques used to determine the amount of PM on urban leaf surfaces, including Graphite Furnace - Atomic Absorption Spectroscopy (GF-AAS) (Esposito et. al, 2018), Flame - AAS (FAAS) (Tavakoli-Hosseinabady et al., 2018), Scanning Electron Microscope - Energy Dispersive Spectroscopy (SEM-EDS) (Deljanin et al., 2015), Inductively Coupled Plasma - Mass Spectroscopy (ICP-MS) (Liang et al., 2017), and ICP - Atomic Emission Spectroscopy (ICP-AES) (Jouraeva et al., 2002). Each of these techniques have their own possible sources of error which could cause many of the inconsistences found in the studies analyzed in this review.

\subsection{Efficiency of Species Accumulation of PM}

Trees have been shown to be considered the most effective type of vegetation for accumulating PM (Deljanin et al., 2015; Jouraeva et al. 2002). One study revealed that this is the case due to their large total leaf surface area (McDonald et al. 2007). It has also been shown that leaves of broad-leaved species with rough surfaces are more effective in capturing PM than leaves with smooth surfaces (Beckett et al., 2000). Additionally, needles of coniferous trees, produce a thicker epicuticular wax layer resulting in being more effective in PM accumulation than broad- 
leaved species (Beckett et al., 1998). According to these studies the ideal urban vegetative species for accumulating PM are species that have large broad-rough leaves and/or a thick epicuticular wax layer. Although these studies have shown that this may be true, other studies have shown that this is inconsistent. Dzierżanowskiz et al., determined that large branchy-leaved trees were the least effective at PM accumulation and multiple studies concluded that small shrubs with dense leaves were the most effective in PM accumulation (Dzierżanowski et al., 2011; Sæbø et al., 2012; Shi et al., 2017; Liu et al., 2018).

\subsection{Different Findings for Same Tree Species}

A study by Jouraeva et. al. demonstrated that leaves of Tilia spp., a Linden tree, possessed a higher ability to remove PM from the atmosphere than leaves from Pyrus calleryana, a pear tree, and that this ability is not associated with leaf size or the amount of wax on leaves, as shown in the Appendix, on page 13. This is inconsistent with a study that concluded that Pyrus calleryana had the highest accumulation of PM (Sæbø et al., 2012). The potential of wax in trapping particles may be dependent more on the chemical composition and structure of the epicuticular wax layer, which are species-specific traits (Post-Beittenmiller 1996; Kaupp et al. 2000; Jouraeva et al. 2002), than on wax quantity. One study also concluded that Tilia spp. was the most effective at accumulating PM (Deljanin et al., 2015), but Sæbø et al. concluded that Tilia spp. had the lowest PM accumulation. Hence, there is no correlation between PM accumulation due to leaf surface roughness or leaf size. These studies demonstrated that there are many variables that need to be considered when determining the most and least effective urban species in PM accumulation.

\subsection{Two Comparable Studies by Dzierżanowski and Sab $\phi$}

Two studies performed in Europe investigated the accumulation abilities of the same urban species, specifically, Tilia cordata a tree, Spiraea japonica and Forsythia $\times$ intermedia Zabel two species of shrubs, and Hedera helix L a climber species, as shown in the Appendix, on page 13 (Dzierżanowski et al., 2011; Sæbø et al., 2012). Dzierżanowski was the chief author in the study that included a fellow researcher Sæbø. They conducted research in Warsaw, Poland and Stavanger, Norway. They used very similar methods for determining the amount of PM found on these different urban species. Both studies used the same analytical technique Gravimetric Analysis to quantify the concentration and composition of PM found on the urban vegetative species analyzed.

Both results concluded that the shrub $S$. japonica with its small dense leaves had the highest total accumulation of PM, as shown in Data Table $1 \& 2$. In addition, they found that $S$. japonica was the most efficient of all the urban species investigated with over a two-fold difference between shrub species at accumulating all types of PM. They believed this was because low-growing species are more exposed to soil splash on the leaves and this could partly explain why $S$. japonica had high amounts of PM found on the leaves (Sæbø et al., 2012). However, a study performed by 
Ottelé et al., did not find any significant differences in PM accumulation between sampling heights over the range of $0.75-2.0 \mathrm{~m}$.

The research presented by Dzierżanowski and Sæbø demonstrates that when using similar methods to determine the concentration and composition of PM found on the surfaces of leaves can produce more accurate and precise results even in different geographical locations. Their studies help support that when conducting research in this area, a system of methodology needs to be implemented to help produce more reliable data and avoid inconsistences in the findings.

Data Table 1: Sabø Data of PM Accumulation for Various Urban Vegetative Species

\begin{tabular}{r|c|c|c|c}
\hline \multicolumn{1}{c|}{ Urban Species } & Large PM $\left(\mu \mathrm{g} / \mathrm{cm}^{2}\right)$ & Coarse PM $\left(\mu \mathrm{g} / \mathrm{cm}^{2}\right)$ & Fine PM $\left(\mu \mathrm{g} / \mathrm{cm}^{2}\right)$ & Total PM $\left(\mu \mathrm{g} / \mathrm{cm}^{2}\right)$ \\
\hline S. japonica & & & & \\
Leaf Surface: & 22 & 13 & 1.5 & 36.5 \\
In-wax: & 17 & 3.3 & 1.1 & \\
\hline Forsythia intermedia & & & & 18 \\
Leaf Surface: & 13 & 3.5 & 1.5 & 13.1 \\
In-wax: & 6.0 & 6.0 & 1.1 & \\
\hline Tilia cordata & & & & 7.4 \\
Leaf Surface: & 3.5 & 2.4 & 1.5 & 7.5 \\
In-wax: & 4.3 & 2.1 & 1.1 & \\
\hline
\end{tabular}

Data Table 2: Dzierżanowski Data of PM Accumulation for Various Urban Vegetative Species

\begin{tabular}{r|c|c|c|c}
\hline Urban Species & Large PM $\left(\mu \mathrm{g} / \mathrm{cm}^{2}\right)$ & Coarse PM $\left(\mu \mathrm{g} / \mathrm{cm}^{2}\right)$ & Fine PM $\left(\mu \mathrm{g} / \mathrm{cm}^{2}\right)$ & Total PM $\left(\mu \mathrm{g} / \mathrm{cm}^{2}\right)$ \\
\hline S. japonica & & & & 16.8 \\
Leaf Surface: & 12 & 3.3 & 1.5 & 10.65 \\
\hline In-wax: & 7.0 & 2.8 & 0.85 & \\
Forsythia intermedia & & & & 9.8 \\
Leaf Surface: & 6.5 & 2.1 & 1.2 & 8.0 \\
In-wax: & 5.0 & 2.0 & 1.0 & \\
\hline Tilia cordata & & & & 11.5 \\
Leaf Surface: & 9.0 & 2.5 & ---- & 9.6 \\
In-wax: & 7.5 & 2.1 & ---- & \\
\hline
\end{tabular}




\section{Conclusion}

My findings do show that there are variations in the literature and that many variables need to be included in the methods and analysis of PM accumulation. Such as, using similar analytical techniques. In addition, the time of year the samples are collected could also have an effect on the results. For example, two studies used the same species and locations but Shi et al., collected samples at the end of the growing season (dry season) and Liang et al., collected samples at the beginning of the growing season (wet season). Their results showed the samples collected at the end of the growing season had a higher concentration of PM. This was likely due to less rainfall eluting the PM off of the surface of the leaves. Therefore, collecting samples at different times of the year will cause uncertainty in the results.

Another factor that should be included in the process of studying PM accumulation is the preparation for analysis of PM. For example, Jouraeva et al., used a hot-acid microwave digestion to remove PM for preparation of analysis and Dzierżanowski et al., implemented a rinse method using deionized water for preparation of analysis. These different methods for preparation demonstrated that Jouraeva et al., used the entire leaf and Dzierżanowski et al., rinsed only the surface of the leaves. This could cause inconsistences in the results because of the amount of the sample used to analyze. This would produce different results in the amount of PM found because using the entire leaf is a larger sample size. These wide ranges of techniques have made it difficult to compare the research and to determine what urban species are most and least effective at accumulating PM. As a result, it makes it difficult in understanding what urban species have the highest efficiency in reducing the amount of PM in urban areas.

Because researchers are not implementing a standardized method for determining the amount of PM found on urban vegetation, we will continue to have disagreements and inconsistent data and results in this field of study. For future research, a standardized method needs to be implemented for analyzing PM found on urban species to help reduce the disagreements. This knowledge will aid in determining which plants and trees can reduce the most harmful pollutants in urban areas and consequently improve air quality. This will also assist landscape architects and planners in designing appropriate vegetation for a particular urban area to remove the greatest amount of PM from the atmosphere. 


\section{References:}

Al-Alawi, M.M. \& Mandiwana K.L. The use of Aleppo pine needles as a bio-monitor of heavy metals in the atmosphere. Journal of Hazardous Materials. 2007. 148:43-46.

André Andre, Paulo Afonso de \& Regina Maura de Miranda, Maria de Fatima Andrade, Adalgiza Fornaro, Rosana Astolfo, Paulo Saldiva. Urban air pollution: a representative survey of $\mathrm{PM}_{2,5}$ mass concentrations in six Brazilian cities. Air Quality Atmosphere Health. 2012. 5(1): $63-77$.

Beckett, K.P. \& Freer-Smith P., Taylor G. Urban woodlands: Their role in reducing the effects of particulate pollution. Environmental Pollution. 1998. 99(3):347-360.

Beckett, K.P. \& Freer-Smith P., Taylor G. Effective tree species for local air quality management. Journal of Arboriculture. 2000. 26(1):12-19.

Burkhardt, Juergen \& David Grantz, Mauricio Hunsche, Shyam Pariyar, Mark Sutton, and Daniel Zinsmeister. Camouflaged as Degraded Wax: Hygroscopic Aerosols Contribute to Leaf Desiccation, Tree Morality, and Forrest Decline. Environmental Research Letters. 2018. 13.

Cao, Liwan \& Erwin Appel, Shouyun Hu, Mingming Ma. An economic passive sampling method to detect particulate pollutants using magnetic measurements. Environmental Pollution. 2015. 205:97-102.

Claiborn, C.S. \& T. Larson, L. Sheppard. Environmental Health Perspectives. 2002. 110:547.

Deljanin, I. \& Antanasijević, Bjelajac, Urošević, Nikolić, Perić-Grujić, Ristić. Chemometrics in biomonitoring: Distribution and correlation of trace elements in tree leaves. The Science of the Total Environment. 2015. 545-546:361-371.

Dzierżanowski, Kajetan \& Popek R., Gawrońska H., Sæbø A., Gawroński S.W. Deposition of particulate matter of different size fractions on leaf surfaces and in waxes of urban forest species. International Journal of Phytoremediation. 2011. 13(10):1037-46.

EPA. Blood Cadmium. Report on the Environmental. United States Environmental Protection Agency. ATSDR (Agency for Toxic Substances and Disease Registry). 2012. Cadmium fact sheet. Division of Toxicology and Environmental Medicine Toxic FAQs. Retrieved from cfpub.epa.gov/roe/indicator_pdf.cfm?i=61.

Esposito, F. Capture Rate of Selected Heavy Metals In Q. Ilex L. Leaves Collected At Two Sites With Different Land Uses. Environmental Accounting and Management. 2018. 6(4):305311.

Farmer, A. Effects of particulates. Air pollution and plant life. 2002. 187-199.

Fowler, D. \& Cape J.N., Unsworth M.H. 1989. Deposition of atmospheric pollutants on forests. Philos. Trans $R$ Soc London. 1989. 324:247-265. 
Gratani, Loretta \& Rosangela Catoni, Laura Varone. Evergreen species response to Mediterranean climate stress factors. Global Challenges of Air Pollution and Climate Change to Forests. 2008. 3:946-953.

Jouraeva, Venera A. \& David L. Johnson, John P. Hassett, David J. Now. Differences in accumulation of PAHs and metals on the leaves of Tilia euchlora and Pyrus calleryana. Environmental Pollution. 2002. 120:331-338.

Kaupp, H. \& M. Blumenstock, M.S. McLachlan. Retention and mobility of atmospheric particleassociated organic pollutant PCDD/Fs and PAHs on maize leaves. New Phytol. 2000. 148(3):473-480.

Liu, Jinqiang \& Ruina Zhang, Huanhuan Liu, Jie Duan, Jia Kang, Zemin Guo, Benye Xi, Zhiguo Cao. Assessing the Particulate Matter Removal Abilities of Tree Leaves. Journal of Visualized Experiments. 2018. doi:10.3791/58026

Liang, J. \& H.L. Fangc, T.L. Zhanga, X.X. Wanga, Y.D. Liu. Heavy metal in leaves of twelve plant species from seven different areas in Shanghai, China. Urban Forestry and Urban Greening. 2017. 27:390-398.

Lindley, S. J. \& Smith, C. L., Speak, A.F., Rothwell, J.J. Atmospheric Environment: Urban Particulate Pollution Reduction by Four Species of Green Roof Vegetation in a UK City. Atmospheric Environment. 2012. 61:283-293.

McDonald, A. G. \& Bealey W. J., Fowler D., Dragosits U., Skiba U., Smith R.I., Donovan R.G., Brett H.E., Hewitt C.N., Nemitz E. Quantifying the effect of urban tree planting on concentrations and depositions of PM10 in two UK conurbations. Atmospheric Environmental. 2007. 41(38):8455-8467.

Nowak, David J. Air pollution removal by Chicago’s Urban Forest. In: McPherson GE, Nowak DJ, Rowntree RA, editors. Chicago's Urban Forest ecosystem: Results of the Chicago Urban Forest Climate Project. USDA General Technical Report NE. 1994. 186:63-81.

Nowak, David J. \& Crane D.E., Stevens J.C. Air pollution removal by urban trees and shrubs in the United States. Urban For \& Urban Greening. 2006. 4:115-123.

Nowak, David J. \& Satoshi, Hirabayashi \& Allison Bodine, Robert Hoehn. Modeled PM2.5 removal by trees in ten U.S. cities and associated health effects. Environmental Pollution. 2013. 178:395-40.

Oliva, Rossini S. \& Mingorance MD. Assessment of airborne heavy metal pollution by aboveground plant parts. Chemosphere. 2006. 65(2):177-182.

Post-Beittenmiller D. Biochemistry and molecular biology of wax production in plants. Annual Rev Plant Physiol Plant Mol Biol. 1996. 47:405-430.

Petroff, A. \& A. Mailliat, F. Anselnet. Aerosol dry deposition on vegetative canopies: Part 1: Review of Present Knowledge. Atmospheric Environmental. 2001. 42:3625-3653. 
Sæbø, A. \& R. Popekb, B. Nawrotb, H.M. Hanslina, H. Gawronskab, S.W. Gawronski. Plant species differences in particulate matter accumulation on leaf surfaces. Science of Total Environment. 2012. 427-428:347-354.

Salvi, S. Health effects of ambient air pollution in children. Pediatric Respiratory Reviews. 2007. 8(4):275-280.

Setälä, Heikki \& Viljami Viippolaa, Anna-Lea Rantalainena, Arto Pennanenb, Vesa Yli Pelkonen. Does urban vegetation mitigate air pollution in northern conditions? Environmental Pollution. 2013. 183:104-112.

Shi, Junna \& Gang Zhang, Hailong An, Weilun Yin, and Xinli Xia. Quantifying the particulate matter accumulation on leaf surfaces of urban plants in Beijing, China. Atmospheric Pollution Research. 2017. 8:836-842.

Speak, A.F. \& J.J. Rothwell, S.J. Lindley, C.L. Smith. Urban particulate pollution reduction by four species of green roof vegetation. Atmospheric Environment. 2012. 61:293-293.

Tavakoli-Hosseinabady, Bita \& Parisa Ziarati, Ebrahim Ballali, Krishnan Umachandra. Detoxification of Heavy Metals from Leafy Edible Vegetables by Agricultural Waste: Apricot Pit Shell. Journal of Environmental \& Analytical Toxicology. 2018. 8(1).

Ugolini, Francesca \& Roberto Tognetti, Antonio Raschi, Laura Bacci. Quercus ilex L. as bioaccumulator for heavy metals in urban areas: Effectiveness of leaf washing with distilled water and considerations on the trees distance from traffic. Urban Forestry \& Urban Greening. 2013. 12(4):576-584.

Whitlow, Thomas H. Comments on "Modeled PM2.5 removal by trees in ten U.S. cities and associated health effects" by Nowak et al. Environmental Pollution. 2014. 191(256).

World Health Organization (WHO). Particulate matter air pollution: how it harms health. Fact sheet EURO/04/05. 2005. Berlin, Copenhagen, Rome: WHO.

Yang, J \& McBride J., Zhou J., Sun Z. The urban forest in Beijing and its role in air pollution reduction. Urban For \& Urban Greening. 2005. 3:65-78.

Zimmerman, Britt \& Holly Zipp. Residential Green Roof Implementation in Washington, DC: A Stormwater Management Tool for an Impervious Urban Environment. Master of Landscape. 2008. Retrieved from natureforcities.snre.umich.edu/wpcontent/uploads/2012/11/Design-Green-Roof-Retrofitting-Stormwater-ManagementWashingtonDC.pdf.

\section{Appendix:}





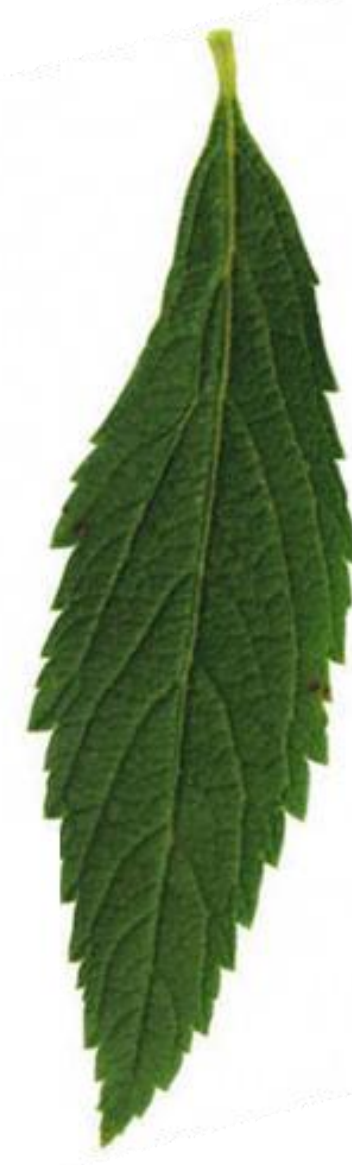

Spiraea japonica (shrub)

KonzeptWerkstatt

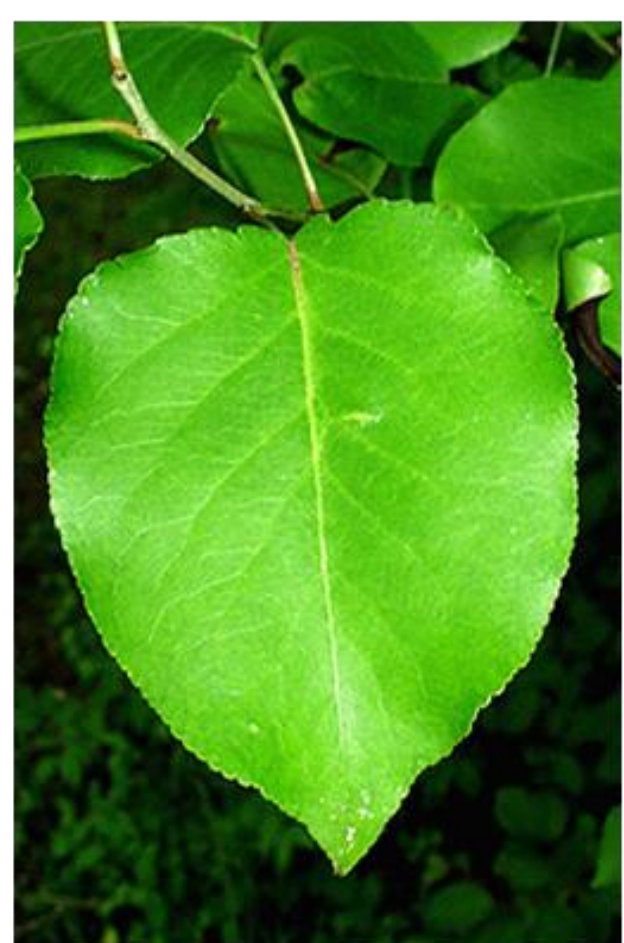

Pyrus calleryana (tree) Dendro

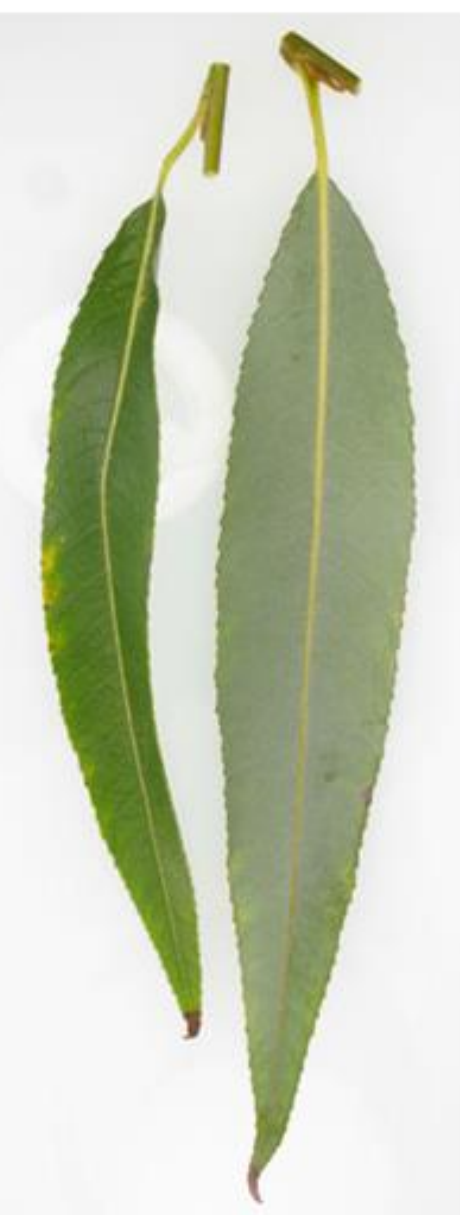

Salix babylonica (tree) Tree Record

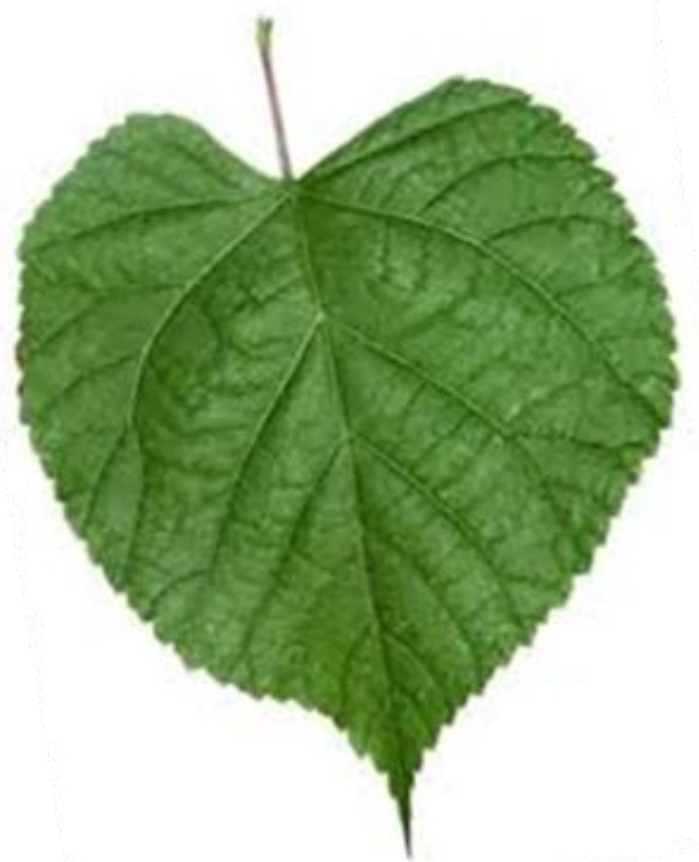

Tilia cordata (tree) Woodland Trust
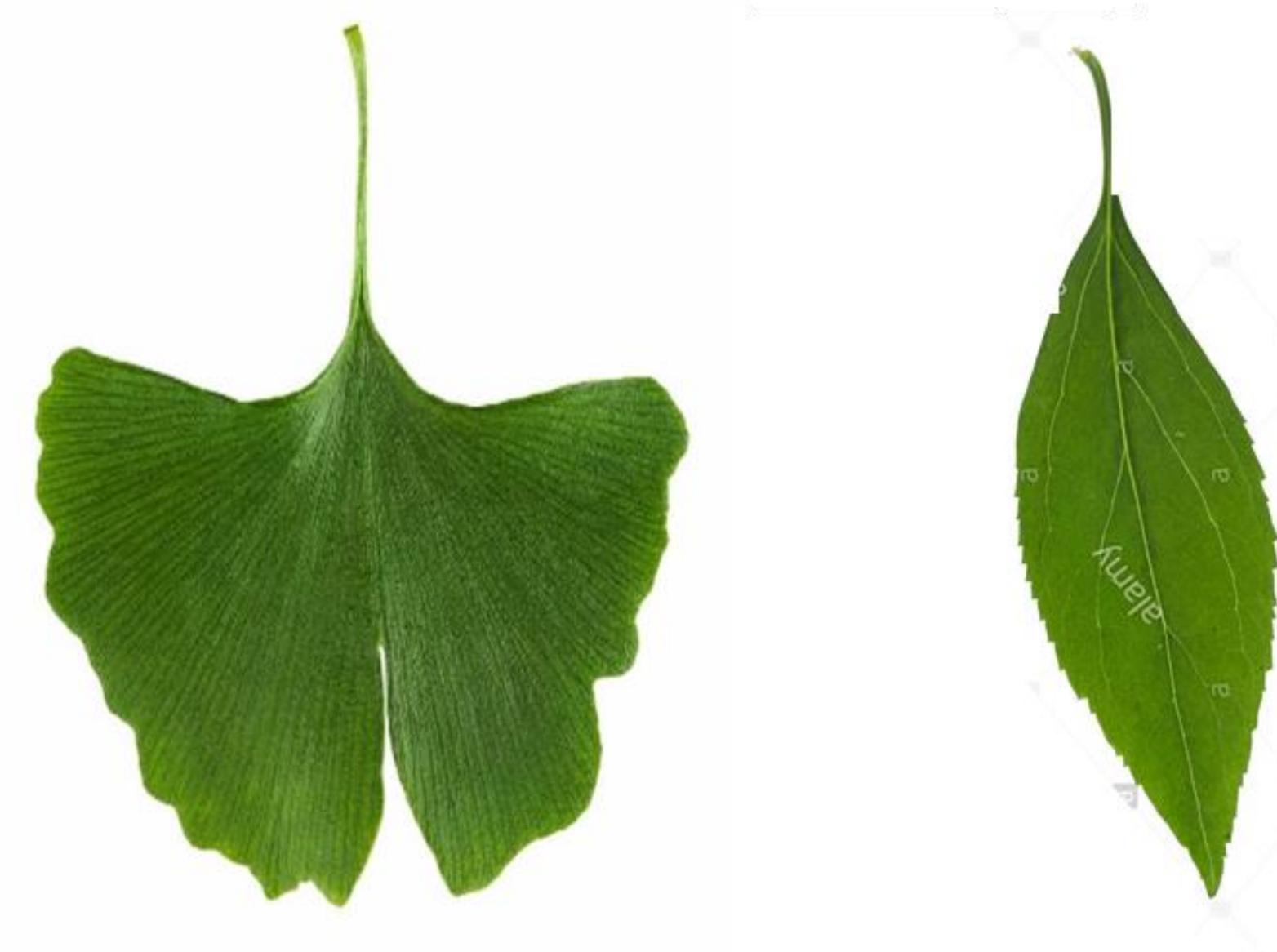

Ginkgo biloba (tree) Forsythia intermedia (tree) SelcetTrees

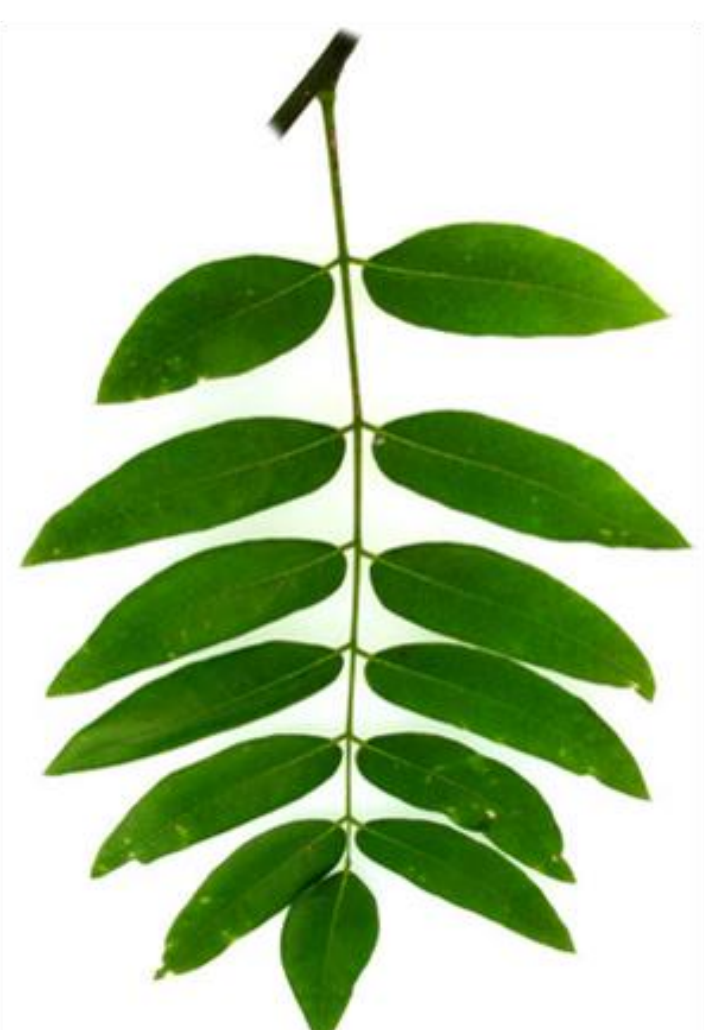

Sophorajaponica (tree)

Pixels

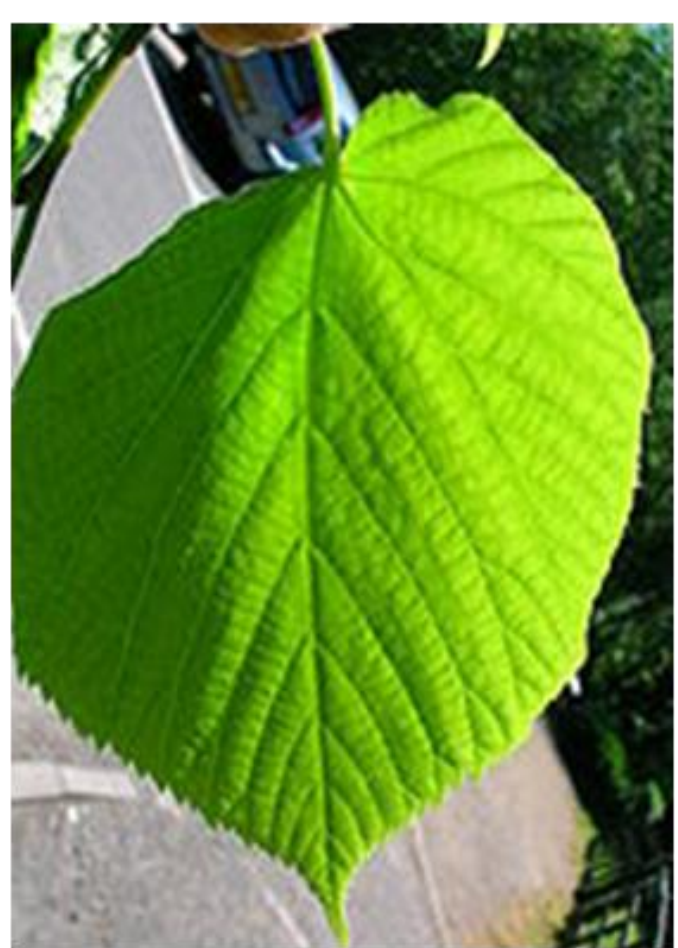

Tilia spp (tree) Pemberton 


\begin{tabular}{|c|c|c|c|c|c|c|c|}
\hline Authors & Year & Publication & Method of Quantification & Sample & Location & Most Effective & Least Effective \\
\hline & & & & $\begin{array}{c}\text { Trees: (Aesculus } \\
\text { hippocastanum, } \\
\text { Tilia spp., Betula pendula, \& }\end{array}$ & & & \\
\hline Deljanin, I. & 2015 & The Science of the Total Environment & SEM-(EDS) & Acer platanoides) & Belgrade, Serbia & Tilia spp. & A. hippocastanum \\
\hline
\end{tabular}

\begin{tabular}{|c|c|c|c|c|c|c|c|}
\hline $\begin{array}{l}\text { Dzierżanowski, } \\
\text { Kajetan }\end{array}$ & 2011 & International Journal of Phytoremediation & Gravimetric Analysis & $\begin{array}{l}\text { Trees: (Acer campestre L., } \\
\text { Fraxinus excelsior L., Platanus } \\
\text { x hispanica Mill. ex Muenchh. } \\
\text { Acerifolia, \& Tilia cordata Mill.) } \\
\text { Shrubs: (Forsythia x } \\
\text { intermedia Zabel, } \\
\text { Physocarpusopulifolius (L.) } \\
\text { Maxim., \& Spiraea japonica L.) } \\
\text { Climber: (Hedera helix L.) }\end{array}$ & Warsaw, Poland & Spiraea japonica & Platanus hispanica \\
\hline Esposito, F. & 2018 & Environmental Accounting and Management & GF-AAS & Tree: (Q. ilex L.) & Naples, Italy & ----- & ---- \\
\hline $\begin{array}{l}\text { Jouraeva, Venera A. } \\
\text { \& David J. Nowak }\end{array}$ & 2002 & Environmental Pollution & ICP-AES & $\begin{array}{l}\text { Trees: (Pyrus calleryana and } \\
\text { Tilia euchlora) }\end{array}$ & Syracuse, NY, USA & Tilia euchlora & Pyrus calleryana \\
\hline Liu, Jinqiang & 2018 & Journal of Visualized Experiments & $\begin{array}{l}\text { Ultrasonic Rinsing and } \\
\text { Gravimetric Analysis }\end{array}$ & $\begin{array}{c}\text { Trees: (Ginkgo biloba, Sophora } \\
\text { japonica, Salix babylonica, } \\
\text { Pinus tabuliformis, \& Sabina } \\
\text { chinensis) }\end{array}$ & Beijing, China & $\begin{array}{l}\text { S. japonica. \& Salix } \\
\text { babylonica }\end{array}$ & $\begin{array}{l}\text { Pinus tabuliformis \& } \\
\text { Ginkgo biloba }\end{array}$ \\
\hline Liang, J. & 2017 & Urban Forestry and Urban Greening & $\begin{array}{l}\text { ICP-MS and supported with } \\
\text { SEM }\end{array}$ & $\begin{array}{l}\text { Trees: (Platanus acerifolia, } \\
\text { Cedrus deodara, Ginkgo } \\
\text { biloba, \& Magnolia } \\
\text { grandiflora) } \\
\text { Shrubs: (Nerium indicum \& } \\
\text { Pittosporum tobira) }\end{array}$ & Shanghai, China & Magnolia arandiflora & Cedrus deodara \\
\hline
\end{tabular}


25 Shrub Species: (Skimmia japonica, Forsythia $\times$ intermedia Zabel,

Sæbø, A.

Gravimetric Analysis

Physocarpusa opulfolus L.

Physocarpusa opulifolius $L$.
Maxim., Pinus sylvestris etc.)

Climber: (Hedera helix L.)

Stavanger, Norway \&

Warsaw, Poland

At both sites: (S. japonica)

Trees: (P. sylvestris \& B.

pendula)
In Norway: (Acer platanoides \& Tilia cordata)

In Poland: (B. pendula \& Pyrus calleryana)

11 Tree Species: (Ginkgo

biloba, Salix babylonica,

japonica, Koelreuteria paniculata, etc.)

Shrubs: (Sorbaria kirilowii and Amygdalus triloba, \& Euonymus japonicus)

Beijing, China

S. japonicus

Both Sites: $(P$

4 greenroof species: (Agrostis stolonifera, Festuca

rubra,Plantago lanceolata, \& Sedum album)

ICP-MS

Grasses: (A. stolanifera and

Weed: (P. lanceolata)

Speak, A.F 